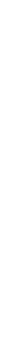

\title{
O PARQUE URBANO BRASILEIRO DO SÉCULO XXI
}

\author{
Francine Gramacho Sakata ${ }^{1}$
}

\begin{abstract}
RESUMO
Parques têm sido projetados e implantados em significativa quantidade nas cidades brasileiras no século XXI porque têm sido percebidos pela população como uma ação 'inteligente' da administração municipal, que preserva o meio ambiente ao mesmo tempo em que valoriza o bairro e amplia as possiblidades de lazer. Mas estes novos parques têm diferenças em relação a seus antecessores. Da mesma forma que a sociedade brasileira mudou neste período, o processo de produção da cidade e suas estruturas morfológicas sofreram alterações.
\end{abstract}

PALAVRAS-CHAVE: Parque Urbano, Paisagismo, Sistemas de Espaços Livres

\section{PARK URBAN BRAZILIAN XXI CENTURY}

\begin{abstract}
RESUME
Parks have been designed and implemented in significant amounts in Brazilian cities in the twenty-first century because they have been perceived by the population as a 'smart' action of the municipal administration, which preserves the environment at the same time enhances the neighborhood and increases the recreational possibilities. But these new parks have differences from its predecessors. In the same way that Brazilian society has changed in this period, the city's production process and its morphological structures have changed.
\end{abstract}

KEYWORDS: Urban Park, Landscape, Space Systems Free

\section{PARQUE URBANO BRASILEÑO DEL SIGLO XXI}

\section{RESUMEN}

Parques se han diseñado e implementado en cantidades significativas en ciudades brasileñas en el siglo XXI, ya que han sido percibidos por la población como una acción "inteligente" de la administración municipal, que preserva el medio ambiente, al mismo tiempo aumenta el barrio y aumenta las posibilidades recreativas. Pero estos nuevos parques tienen diferencias con respecto a sus predecesores. De la misma manera que la sociedad brasileña ha cambiado en este período, el proceso de producción de la ciudad y sus estructuras morfológicas han cambiado.

PALABRAS-CLAVE: Parque Urbano, Paisaje, Space Systems gratis

\footnotetext{
${ }^{1}$ Arquiteta e Urbanista, doutoranda FAU USP. francinesakata@gmail.com
} 


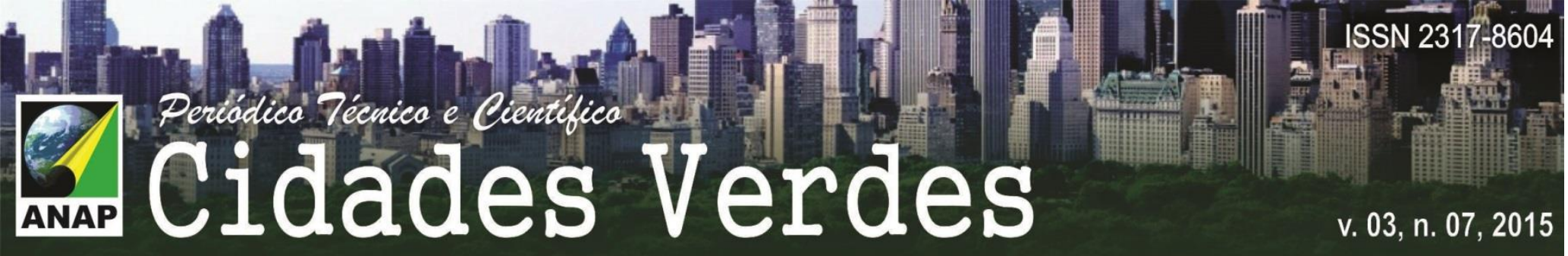

\section{INTRODUÇÃO}

Parques têm sido projetados e implantados em significativa quantidade nas cidades brasileiras no século XXI porque têm sido percebidos pela população como uma ação 'inteligente' da administração municipal, que preserva o meio ambiente ao mesmo tempo em que valoriza o bairro e amplia as possiblidades de lazer. Mas estes novos parques têm diferenças em relação a seus antecessores. Da mesma forma que a sociedade brasileira mudou neste período, o processo de produção da cidade e suas estruturas morfológicas sofreram alterações.

\section{FUNÇÕES}

Os primeiros e mais tradicionais parques das capitais brasileiras nasceram no final do século XIX por inspiração das capitais europeias, visando o embelezamento urbano e a representação das elites. A partir das décadas de 1940 e 1950, com a intensa urbanização, os novos hábitos culturais e a diminuição dos espaços vazios que podiam ser usados para o lazer, a figura do parque público multifuncional foi ganhando importância. ${ }^{2}$

Nos anos de 1970 e 1980 que a criação de parques nas grandes cidades se torna de fato um objetivo do poder público e isto se torna sistemático. Parte significativa dos parques de São Paulo, do Rio de Janeiro e de Curitiba são deste período.

Paralelamente, a partir do final do século passado e, de forma cada vez mais perceptível, a consciência ambiental foi se ampliando. As novas gerações têm claro que os recursos naturais são limitados e que é preciso tomar providências para não esgotá-los. Mas a necessidade da alteração do atual padrão de consumo não é uma questão levada aos cidadãos-consumidores. Já a criação e o uso de parques são ações amplamente divulgadas como ambientalmente corretas. Este consenso em

\footnotetext{
${ }^{2}$ MACEDO e SAKATA, 2001.
} 
bosque a preservar, receberam atenção. Foi mais uma questão de oportunidade que de necessidade das pessoas. Não se tratou de planejamento urbano. Como resultado, a zona leste não recebeu quase novos parques. Em Campo Grande a realidade é diferente. Um plano do final da década de 1970 delimitou áreas para um sistema de parques lineares que foram implementados a partir de 2000.

Os novos parques paulistanos foram pagos (projeto e obra) com recursos de compensações. Os TCAs - Termos de Compensação Ambiental pagos à Prefeitura de São Paulo pelos cortes de árvores em empreendimentos imobiliários acabaram sendo uma forma do poder público ter acesso ao capital imobiliário (inclusive recursos do FGTS) que está nas mãos das construtoras e incorporadoras. Neste caso, o poder público, via Secretaria de Meio Ambiente (Depave I) manteve o controle sobre a concepção e o projeto. Como princípio, acreditamos que o Estado não pode perder este papel - já bastante reduzido - de controlar o investimento no espaço público.

\section{ESTUDOS DE CASO}

PARQUE LINEAR DO CÓRREGO CABUÇU DE CIMA. Este parque ainda não implantado, concebido pela Prefeitura de São Paulo e com projeto básico foi desenvolvido pela NK\&F Arquitetura da Paisagem, está situado em uma área lindeira a um córrego retificado, ocupada por um conjunto de ruas residenciais e praças, um conglomerado urbano consolidado e desqualificado para a implantação de um parque. É um conjunto de praças e áreas livres desconectados e sem equipamentos, ruas asfaltadas com poucos trechos arborizados e raríssimas áreas permeáveis. Mas, por se tratar, em tese, de uma área de preservação permanente, as ruas vizinhas ao córrego foram reprojetadas como vias traffic calming, para circulação de veículos dos moradores apenas, compartilhadas com pedestres e ciclistas. As praças foram englobadas pelo "parque", com pisos para usos de lazer, playground e equipamento para ginástica. Resultou em um conjunto de calçadasruas e pequenas pracinhas interligadas, identificadas como parque linear, onde nunca se perde a relação com o urbano, o que seria a característica essencial do 


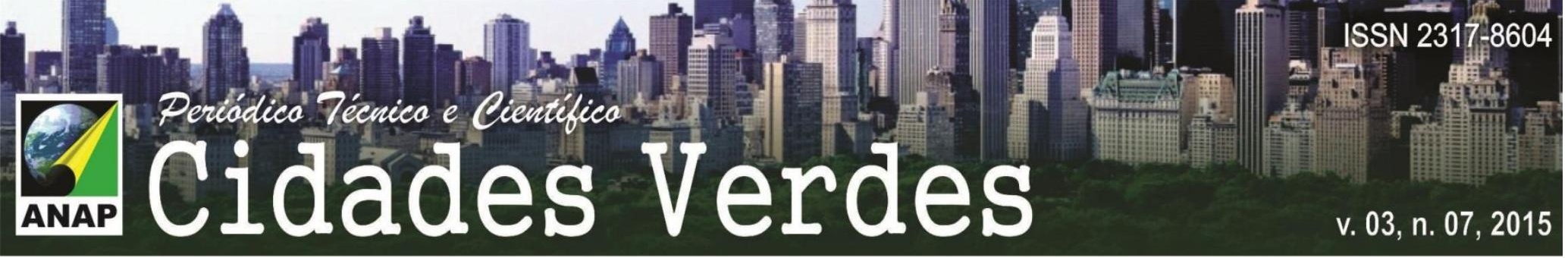

goiano é recuperar um espaço socioambientalmente degradado, que tem recebido esgoto residencial e industrial e entulho, convertendo-o em um benefício para 131 bairros relativamente densos percorridos pelo parque. Ao longo do parque seriam implantados equipamentos de lazer e sedes de convivência comunitária. Pode-se dizer que esta é uma ação de planejamento urbano através de um parque.

Figura 2: Projeto do Parque Macambira-Anicuns
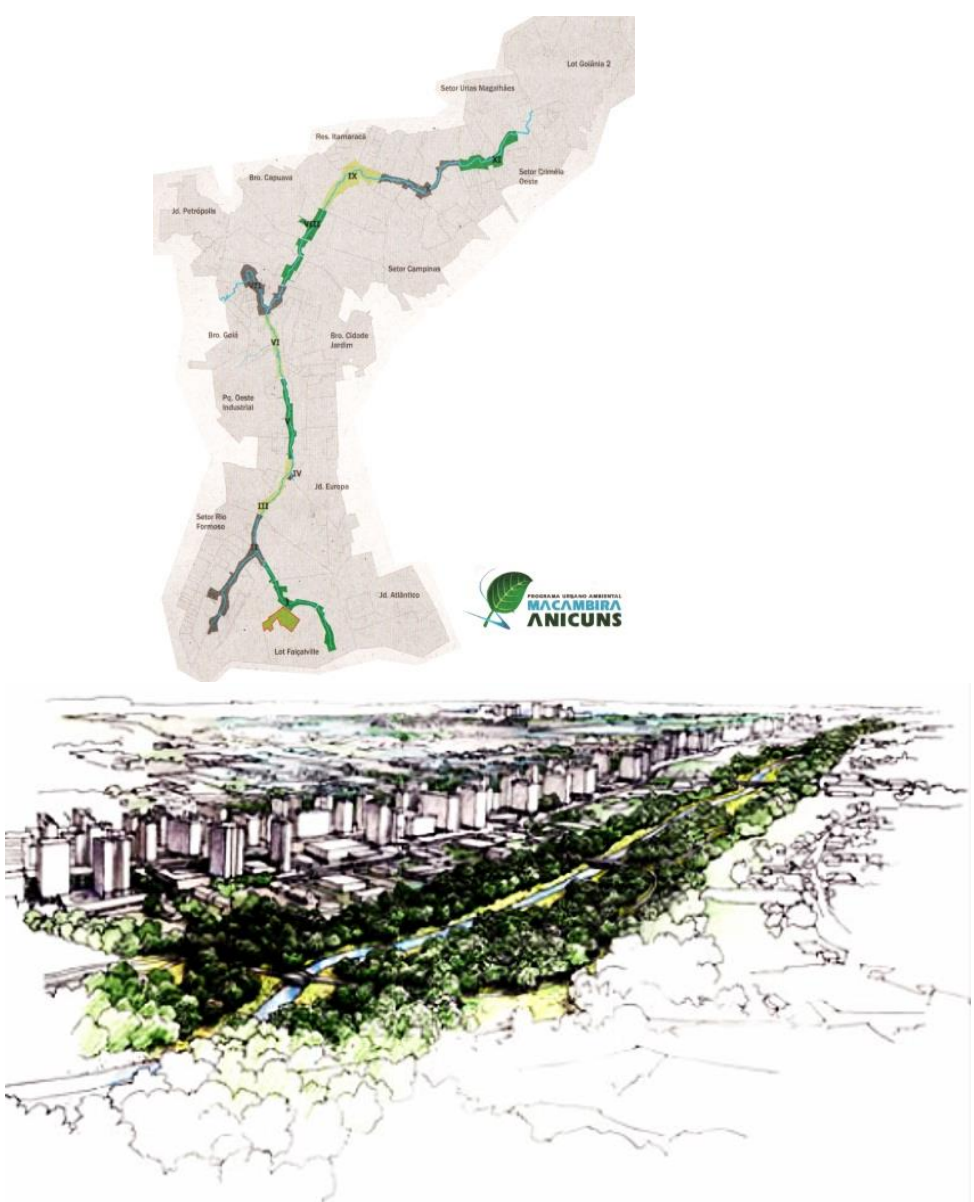

Fonte: Memorial do projeto, Barbieri \& Gorski. 2013

PARQUE MADUREIRA. Trata-se de um parque linear, porque se desenvolve paralelo a linhada ferrovia e de transmissão de energia. Ocupa o lugar de uma favela, cujo desmonte deu com o descumprimento de acordos do Estado para com a população residente, na linha de outras desapropriações no âmbito das 


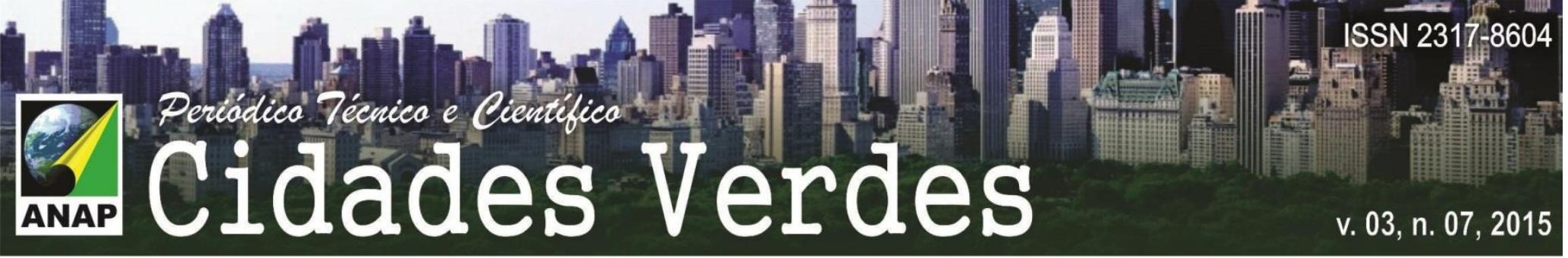

obras do "Rio Olímpico". Como nos empreendimentos de torres corporativas, buscou-se uma certificação ecológica para a obra. Apesar deste selo ambiental, o parque não conta com bosques ou charcos preservados. É até bastante construído, fazendo uma referência aos térreos de prédios residenciais, preenchidos com muitos equipamentos diferentes. Mas, graças à sequencia de equipamentos com qualidade para o uso, como cascata para uso infantil, prainha, uma imensa pista de skate, bares e palcos para a música mas, principalmente, dada a imensa demanda desta região o parque é um grande sucesso.

Figura 3 e 4: Parque Madureira, no Rio de Janeiro.
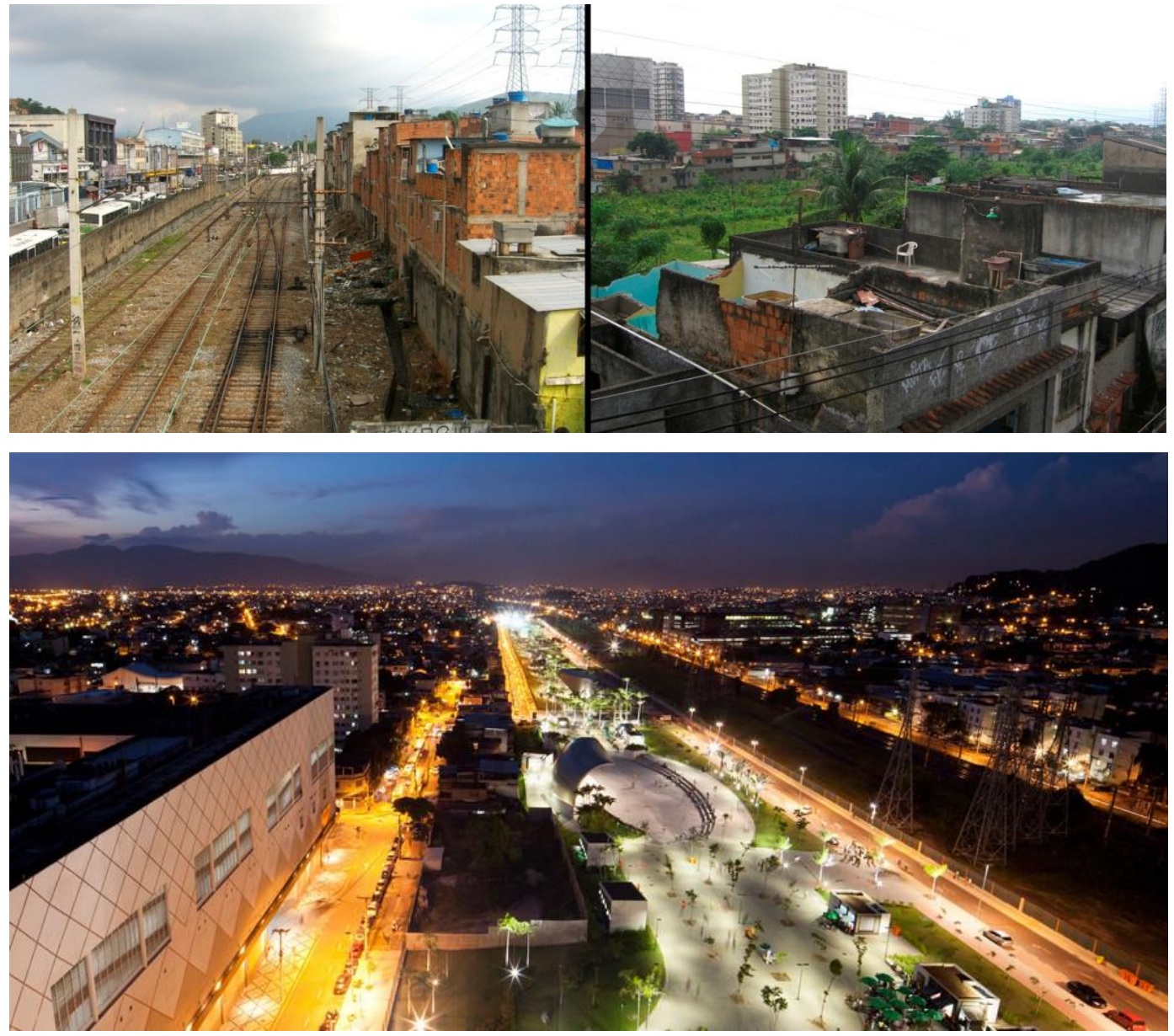

Fonte: Rio On-Watch (favela) e RRA Arquitetura (foto noturna). 2012 


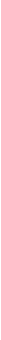

\section{CONCLUSÕES}

A partir da premissa de que parques são elementos estruturadores dos sistemas de espaços livres das cidades contemporâneas brasileiras, devemos avaliar:

- o papel e a importância da vegetação, da drenagem e do lazer nas paisagens urbanas brasileiras, especialmente dentro do parque urbano, esperamos contribuir para equilibrar demandas sociais e ambientais. Como coloca Eugênio Queiroga, os projetos e obras de modo geral precisam estar mais atentos à questão ambiental e os projetos ambientais devem ser mais sensíveis às questões sociais.

- que a distribuição dos parques pela malha urbana não é homogênea e grandes extensões não contam com parque algum. Considerando-se também a mobilidade da população, a locação dos novos parques é feita por circunstâncias políticas e conveniências e não tem necessariamente relação com a demanda de uso da população. É preciso chamar a atenção para desequilíbrios e populações desatendidas.

- os parques urbanos têm sido projetados e implantados em significativa quantidade nas cidades brasileiras no século XXI por conta de um consenso (que conduz a programas e políticas de governo) de que "parque urbano" é uma investimento público que preserva o meio ambiente ao mesmo tempo que valoriza o bairro e amplia as possiblidades de lazer. Mas o poder público tem investido em parques com pouco controle do resultado. Às vezes é um sucesso duradouro, outras vezes não. Ao discutir a origem, o financiamento, a produção $e$ o projeto de parques no Brasil no período de 2000 a 2014, devemos ter maior clareza sobre o que Estado está fazendo (ou deixando de fazer), sobre a garantia e validade deste investimento. 


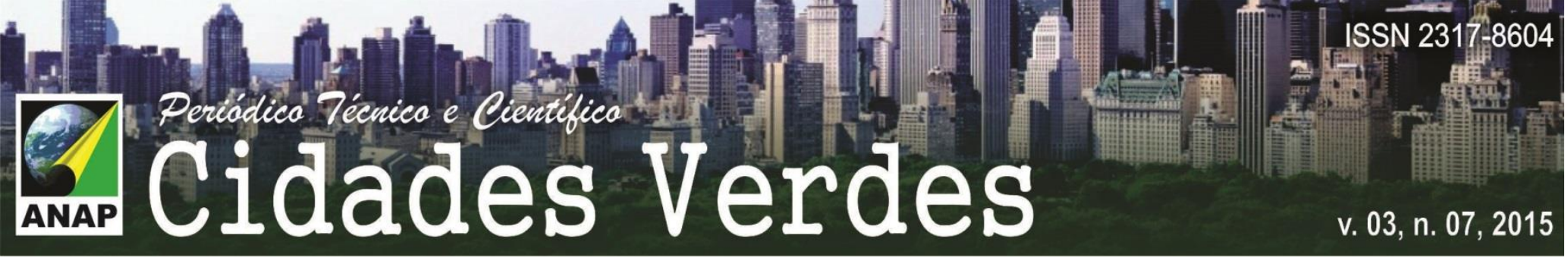

\section{REFERÊNCIAS}

CAMPOS, A. C. A. (Org.) ; QUEIROGA, E. F. (Org.) ; GALENDER, F. (Org.) ; DEGREAS, H. N. (Org.) ; AKAMINE, R. (Org.) ; MACEDO, S. S. (Org.) ; CUSTODIO, V. (Org.) . Quadro dos sistemas de espaços livres nas cidades brasileiras. 1. ed. São Paulo: FAUUSP, 2012.

CAMPOS, A. C. A. (Org.) ; QUEIROGA, E. F. (Org.) ; GALENDER, F. (Org.) ; DEGREAS, H. N. (Org.) ; AKAMINE, R. (Org.) ; MACEDO, S. S. (Org.) ; CUSTODIO, V. (Org.) . Sistemas de espaços livres: conceitos, conflitos e paisagens. 1. ed. São Paulo: FAUUSP, 2011.

CARVALHO, Sidney Vieira. Forma urbana e sistema de espaços livres. Dissertação (Mestrado) Programa de Pós Graduação FAUUSP, São Paulo, 2011.

FARAH, Ivete, SCHLEE, Mônica Bahia e TARDIN, Raquel (orgs.). Arquitetura Paisagística Contemporânea No Brasil. São Paulo: Editora SENAC, 2010.

GALENDER, Fany. Uma contribuição ao estudo do Sistema de Espaços Livres do município de São Paulo. São Paulo: FAUUSP, 2012.

MACEDO, Silvio Soares. Quadro do Paisagismo no Brasil. São Paulo, 1999.

(org.). Paisagem e Ambiente - Ensaios. São Paulo: 1995-2011, v.1- v. 27.

e SAKATA, Francine. Parques Urbanos no Brasil. São Paulo: Edusp, 2001.

NAMIKI, Fábio. Manutenção de praças públicas. Dissertação (mestrado) - Instituto de Pesquisas Tecnológicas do Estado de São Paulo, 2005.

QUEIROGA, Eugenio. A esfera pública contemporânea e os espaços livres: contribuições para o estudo de sistemas de espaços livres nas cidades brasileiras. In: ENCONTRO NACIONAL DA ASSOCIAÇÃO NACIONAL DE PLANEJAMENTO URBANO E REGIONAL, XIII, 2009, Florianópolis. Anais do XIII ENANPUR, Florianópolis, 2009. Sessão Livre. No prelo.

QUEIROGA, Eugenio. Dimensões públicas do espaço contemporâneo: resistências e transformações de territórios, paisagens e lugares urbanos brasileiros. Tese (livre-docência) - Faculdade de Arquitetura e Urbanismo da Universidade de São Paulo. São Paulo, 2012.

QUEIROGA, E., MACEDO, S., CAMPOS, A.C., et. al. Notas gerais sobre o sistema de espaços livres da cidade brasileira: V Colóquio QUAPÁ-SEL. Anais. São Paulo: FAUUSP, 2010. CD-ROM.

QUEIROZ, Alessandra Natali, QUEIROGA, Eugenio Fernandes. Novos processos urbanos e a implantação de parques regionais contemporâneos: estudo de caso na região de Limeira - SP. In: 10은 ENEPEA - Encontro Nacional de Ensino de Paisagismo em Escolas de Arquitetura e Urbanismo no Brasil. Anais. Porto Alegre: PUC-RS, 2010. p. 1-12. CD-ROM.

ROBBA, Fábio e MACEDO, Silvio Soares. Praças Brasileiras. São Paulo: Edusp, 2001.

SAKATA, Francine. Paisagismo Urbano: Requalificação e criação de imagens. São Paulo, EDUSP, 2011.

TAKAESU, Luciana Satiko. Programa 100 parques para São Paulo: áreas de preservação permanente e acessibilidade nos parques urbanos. Monografia - Faculdade de Arquitetura e Urbanismo da Universidade de São Paulo - 2014. 
